\title{
DWORKIN E A RAZOABILIDADE DA JUSTIÇA
}

\author{
Eduardo Carlos Bianca Bittar
}

Resumo:

A partir da obra Taking rights seriously, de Ronald Dworkin, trata-se de discutir e enfatizar a existência de parâmetros para o desenvolvimento prático-judicial da justiça, enquanto fenômeno que é fruto da tradição e que $\dot{i}$ fruto da criação interpretativa. A investigação circunscreve a idéia de razoabilidade e coerência, na perspectiva de uma discussão de principios, como pano de fundo para discutir a abertura dos juizos de decisão jurídica, e o próprio conceito de Direito.

Palavras-chave: Justiça. Hermenêutica. Razoabilidade. Interpretação. Coerência. Dworkin. Filosofia do Direito. Direito.

\begin{abstract}
:
From Dworkin's work intitled Taking Rights Seriously, this article aims to discuss and to enhance the existence of parameters to the practical and judicial development of justice, as a fact origined from tradition and constructive works. This paper circunscreves the idea of reasonability and coherence. from the point of view of discussion of principles, as background to discuss the opening of judgments of legal decisions, as well as the own concept of law.
\end{abstract}

Keywords: Justice. Hermeneutics. Reasonability. Construction. Coherence. Dworkin. Philosophy of Law. Law

1. Dworkin em face do positivismo: à guisa de introdução

O debate sobre a razão prática jurídica pode ser traduzido pela problemática da necessidade de responder ao chamado desafio kelseniano, ' ou seja, à lacuna reflexiva que fica no rastro da discricionariedade hermenêtica concedida por Kelsen ao juiz, na Teoria Pura do Direito, a partir da idéia de interpretação autêntica, e à sua inadvertida negação de fixação de critérios (principios, valores, conceitos...) para a determinação do juízo jurídico-judicial. ${ }^{2}$ É de notável importância ter em Dworkin um contraponto conceitual à mais do que sedimentada conjuntura politica e filosófica do positivismo

Professor Associado do Departamento de Filosolia e Teoria Geral do Direito da Faculdade de Direito da Universidade de São Paulo; Professor Tilular de Filosofia do Direito da FAAP. Professor Doutor e Pesquisador do Programa de Direitos Humanos do UnifIEO. Professor Doutor do Programa Interdisciplinar de Pós-Graduação da Universidade São Marcos.

1 O desafio está posto em FERRAZ JUNIOR, Tércio Sampaio. Introdução ao estudo do direito. 3. ed. São Paulo: Atlas, 2001. p. 257-260.

2 Cf. MURIC'Y, Marilia. Racionalidade do direito, justiça e interpretação. In: BOUCAULT, Carlos E. de Abreu: RODRIGUEZ, José Rodrigo. llermenêulica Plural. São Paulo: Martins Fontes, 2002. p. 119. 
jurídico; não é por outro motivo que se recorre a este pensador norte-americano, Professor de Teoria Geral e Jurisprudência da Universidade de Nova York (Fstados Unidos da América) e da Universidade de Oxford (Inglaterra), com suas reflexões baseadas na tradição anglo-saxã, isto porque se pretende discutir ao longo desta investigação o problema da relação entre a lógica da racionalidade e a lógica da razoabilidade.

Certamente, quando Dworkin está se postando ante seu objeto de estudo. o Direito, não o faz a partir das mesmas premissas que inspiraram a formação e o lastro das concepções classicamente modernas ${ }^{3}$ - sum contradição de termos - do direito contemporâneo. Sua postura é já problematizante, e considera o Direito como um fenômeno de profundo interesse especulativo, o que o motiva a dizer, como o disse de fato em uma conferência no Japão: "É minha visão, de fato, que o Direito é em grande parte filosofia" ${ }^{4} \mathrm{E}$ é esta visão problematizante que fará dele um autor que, ao pensar a questão da interpretação, se torna referência fundamental para a cultura hermenêutica contemporânea, especialmente por representar um contraponto de inigualável valor para a crítica e a contraposição ao modelo do positivismo jurídico e à analítica do discurso jurídico, de civil law (Hans Kelsen e Norberto Bobbio) ou de common law (John Austin e Herbert L. A. Hart). ${ }^{5}$

Quando Dworkin está se postando em face do positivismo, não está somente negando uma matriz de pensamento e suas principais estruturas de raciocínio, mas está, acima de qualquer coisa, se antepondo à lógica dos dois maiores representantes desta vertente de pensamento jusfilosófico, Kelsen e Hart, que ocuparam o espaço da jusreflexão do século XX. Alćm disso, ao reacender o debate sobre pontos frágeis do positivismo, automaticamente, Dworkin reacende a labareda que o faz colocar-se também em face do jusnaturalismo e do pragmatismo. ${ }^{6}$ Muito menos se pode deixar de considerar que Dworkin. ao propor uma reflexão sobre o Direito (Taking rights seriously; Law s

\footnotetext{
A teoria clássica pensa o problema do procedimento decisório em duas etapas, considerando aquela cm que investiga o direito positivo, à busca da solução regrada, e, em nảo havendo, abre-se à admissào do puro arbítrio: "Como já afirmei, a teoria do direito clássica pressupõe que os juízes decidam os casos em duas etapas: encontrem o limite daquilo que o direito explicito exige e, em seguida, exerça um poder discricionário independente para legislar sobre problemas que o direito não alcance" (Dworkin, Levando os direiros a sério. 2002. p. 195).

4 DWORKIN, Ronald. Direito, filusofia e interpretação. Cadernos da escola do legislativo, Belo Horizonte, $v$. 3, n. 5, p. 44-71, jan./jun. 1997. p. 71.

5 Se posicionando desta forma em exposiçâo oral numa palestra em róquio, é que Dworkin (Direito, filosofia e interpretação. Cadernos da escola do legislativo, Belo Horizonte, v. 3, n. 5. p. 44-71, jan./jun. 1997. p. 48) se identifica do ponto de vista teórico.

${ }^{6}$ A sintética mensagem a scguir dá conta da postura de Dworkin ante as divergentes teorias: "Recordemos brevemente aqui que o filósofo tenta traçar para a teoria do direito uma terceira via que superasse por um lado as teses positivistas (o convencionalismo). por outro as teses do pragmatismo e também do jusnaturalismo" (BILLIER, Jean-Cassien; MARYIOLI. Aglaé. Hisı́ria da filosofía do direito. Tradução Maurício de Andrade. São Paulo: Manole, 2005. p. 428).
} 
empire), está em verdade acenando não somente com uma proposta de contra-marcha com relação ao positivismo, mas, sobretudo abrindo um espaço de interlocução que haverá de encontrar fértil manancial de trocas intelectuais com Ncil MacCormick. Jürgen Habermas ¿ John Rawls. ${ }^{7}$

Dworkin irá rebelar-se contra o pragmatismo utilitarista que raciocina pelas soluções sociais imediatistas, assim como envidará fortes esforços para escapar a uma argumentação tipicamente positivista que acaba por justificar o sistema jurídico a partir de si mesmo, ou a partir de uma hipótese meta-modelar. Apesar da crítica se voltar contra sua teoria do juiz-Hércules, como se verá adiante, sua reflexão não necessita, para justificar o funcionamento do ordenamento jurídico desta figura, como a teoria de Kelsen, da norma fundamental para dela derivar toda a fundamentação de validade do sistema ("A norma fundamental de uma ordem jurídica não é de forma alguma uma norma de justiça. Por isso, o direito positivo, isto é, uma ordem coativa criada pela via legislativa ou consuetudinária e globalmente eficaz, nunca pode estar em contradição com a sua norma fundamental, ao passo que esta mesma ordem pode muito bem estar em contradição com o direito natural, que se apresenta com a pretensão de ser o direito justo"), ${ }^{\gamma}$ ou, como a teoria de Hart, que necessita da idéia de regra de reconhecimento para fundamentar a aceitação da legislação como parâmetro de condução de todo o ordenamento ("Na maioria esmagadora dos casos, a fórmula seja o que for que a Rainha no Parlamento promulga é lei' é uma expressão adequada da regra respeitante à competência jurídica do Parlamento e é aceite como critério último de identificação do direito, por mais abertas que possam ser as regras assim identificadas na respectiva periferia").

Disto surgirá uma reflexão curiosa e vanguardista, que reafirma a importância de Wittgenstein e de Heidegger, e que se desconecta das pretensões teóricas dedutivistas ao estilo de Kant ou de Hegel. Isto é que confere um 10 especial ao raciocínio de Dworkin, que, apesar de se basear na linguagem de common law, não se circunscreve ao seu universo de problemas, na medida em que se pode mundializar, com toda pertinência, servindo como instrumento crítico apropriado para a reflexão em civil law. Este tom especial decorre da peculiaridade de seu pensamento, a uma só vez liberal (porque afirmador de direitos individuais ante-estatais), e, ao mesmo tempo, preocupado

Cf. PILON, Almir José; DUTRA, Delamar José Volpatn. Filosofia jurídica contemporânea, justiça e dignidade do ser humano: John Rawls e Ronald Dworkin. In: WOLKMER, Antonio Carlos. (Org.) Fundanentos do humanismo juridico no Ocidente. São Paulo/ Florianópolis: Manole / Fundação Boiteux, p. 182.

8 KELSEN, Hans. O problema da justiça. Tradução de João Baptista Machado. 3. ed. São Paulo: Martins Fontes, 1998. p. 117.

9 HART, H. L. A. O conceito de direito. Tradução de A. Ribeiro Mendes. I isboa: Fundação Calouste Gulbenkian, 1986. p. 162. 
com questões de justiça distributiva e solidarismo social, portanto, bem colocado para a sua inserção entre as discussões dos últimos anos travadas no espaço da Filosofia do Direito, especialmente ante o falencismo pós-moderno demonstrado pelo modelo tcórico, moderno por excelência, do positivismo jurídico, para responder às grandes aflições de justiça de nossos tempos, bem como aos grandes desafios hermenêuticos decorrentes do próprio colapso do Estado Moderno. ${ }^{10}$

Dworkin está longe de trabalhar com uma idéia de razão total (ou totalizante, que acaba, geralmente, no próprio totalitarismo político), que segue o esquematismo da lógica moderna, para a qual tudo se deduz de matrizes decisionais antepostas pela racionalidade legal. $O$ imperialismo da lei, portanto, representando a força hegemônica do Estado-burocracia (Weber), e da racionalidade culminante do processo de amadurecimento do espírito (Hegel), acaba por construir todos os modos pelos quais a razão jurídica pode (e deve) atuar. Isto culmina na execração (corrente no século XIX) de todo tipo de processo criativo por parte do juiz, que deve se circunscrever à decisão já calculada pelo sistema de direito positivo na antecipação feita pelo legislador racional (onisciente, onipotente, racional, sistemático, econômico, prudente...). " Ao mesmo tempo ım que o pensamento de Dworkin é crítico da racionalidade sistemática que torna obtuso o processo de decisão judicial, e, portanto, o modo de exercício da lógica judicial, nem por isso descamba numa reflexão que acaba por abrir campo à política judicial, o que, por conseqüência, abriria lugar para uma aventura discricionária no esteio do processo de condução das práticas jurídicas. No debate entre juridicização da política e politização da justiça. Dworkin estaria entre aqueles que não advogam nem uma coisa nem outra, mas muito menos apela para a típica atitude positivista negadora dos laços recíprocos entre direito e política, assim como entre direito e moral.

Dworkin haverá sim de vergastar a tese fundamental da mentalidade positivista, a sabır, a de que o juízo jurídico não se faz sem o juízo moral. ${ }^{12}$ Se o positivismo fazia crer, especialmente influenciado pelo pensamento kantiano que principia a construção que culmina com a separação entre o ser (Sein) e o deve-ser (Sollen) de

in F. claro que isto tudo o faz reconhecer as dificuldades de operar com as exigencias de um sistema que leve a sério os direitos: "No entanto. é claro no pensamento humanista de Dworkin a dicção de que levar direitos a sério é mais caro para a sociedade do que não os levar, ao trocá-los por benefícios utilitaristas" (PILON. Almir Josí; DL!TRA, Delamar José Volpato. Filosofia jurídica contemporânea, justiça c dignidade do ser humano: John Rawls e Ronald Dworkin. In: WOLKMER, Antonio Carlos. (Org.) Fundamentos do humanismo juridico no Ocidente. São Paulo/ Florianópolis: Manole / Fundação Boiteux, p. 206).

11 A respcito da figura do legislador racional, consulte-sc FERRAZ JUNIOR, Tércio Sampaio. Introdução ao estudo do dircilo. 3. ed. São Paulo: Atlas, 200I. p. 280 e BITTAR, Eduardo C. B. Lingiagem iurídica. 2. ed. São Paulo: Saraiva, 2003. p. 125.

12 SALDAÑA, Javier. Derechos morales o derechos naturales. Boletin Mexicano de Derecho Comparado. Universidad Autónoma de México. México, n. 90. p. 1.217, sept.-nov. 1997. 
Kelsen, que Direito e Moral eram esferas que poderiam ser metodologicamente separadas para a cognição e fundamentação das práticas jurídicas ("A exigência de uma separação entre Direito e Moral, Direito e Justiça, significa que a validade de uma ordem jurídica positiva é independente desta Moral Absoluta, única válida, da Moral por excelência, de $a$ Moral"), ${ }^{13}$ Dworkin irá exatamente abrir uma frente de trabalho onde nega ostensivamente dar continuidade a este raciocínio. Dworkin não vai de encontro ao sistema jurídico vigente para afirmar a inexistência de parâmetros judiciais ou conceder uma carta em branco aos juízes para julgar. Muito menos, Dworkin fará com que o juiz esteja desatrelado da ordem positiva e da necessidade de garantir direitos individuais. ${ }^{14}$

Dworkin se posicionará. do ponto de vista ontológico. contra a vertente positivista exatamente por não admitir nenhum tipo de fundamentação de metalinguagem externa para a existência do Direito, ${ }^{15}$ como uma regra de reconhecimento (que far com que a comunidade reconheça a autoridade de algum órgão ao qual se atribui o poder de cmanar regras válidas), em Hart, ou uma norma fundamental (que faz com que tudo se vincule logicamente ao princípio sintático e hierárquico de relacionamento entre as validades das normas jurídicas), em Kelsen. ${ }^{16}$ Dai sua relevância para a crítica hermenêutica hodierna às matrizes do positivismo jurídico.

2. A atividade interpretativa: razões e desrazões da justiça

A justiça não pode ser construída fora da linguagem. Este é um dado inegável para a reflexão jusfilosófica que assume problımatizar a interpretação na esfera das práticas jurídicas. Não por outro motivo, o Direito não é visto como uma investigação, especialmente no processo, que reconstrói dados do passado, como um historiador o faria, mas sim um tipo de atitude investigativa sobre a realidade que realiza interpretações sobre fatos ocorridos e juridicamente relevantes. dentro de um contexto decisório. O Direito é, assim, considerado. em sua teoria, fato interpretativo que depende visceralmente das necessidades da prática social comunitária e institucional dos agentes de justiça. ${ }^{17}$

13 KEI.SEN. Hans. Teoria pura do direilo. Traduçâo de João Baptista Machado. 4. ed. ('oimbra: Armênio Amado Editor, 1976. p. 104.

i4 Cf. ROMERO. Marcelo Troncoso. Ronald Dworkin: sobre la teoría de la función judicial. Revista de Derecho. Universidad de Concepción, n. 193, p. 101-105, enero-junio, 1993.

15 Cf. SILVA FILHO, José Carlos Moreira da. Dworkin e os principios: os avanços da hermenêutica critica do direito. Fstudos juridicos, v. 31, n. 81, p. 73-94, jan.iabr. 1998.

16 Cf. DWURKIN. Ronald. Direito, inlosofia e interpretaçào. Cadernos da escola do legislativo. Belo Horizonte, v. 3, n. 5. p. 44-71, jan./jun. 1997.

1. "O Dircito, antes de ser um exemplo de regras que se aplicam ora de maneira mecânica (easy cases), ora de maneira 'refletida' nos casos dificeis, é mais a atitude interpretativa de uma comunidade que realiza a justiça. Antes do direito como sistema de regras existe a idéia de direito, o direito como justiça" (BILLIER. Jean- 
Entenda-se, no entanto, que interpretação, no sentido assumido por Dworkin, não é nem criação ex nihilo e nem mesmo ato de vontade da autoridade decisória. Interpretação parcce significar a retomada do sentido social. sob as circunstâncias de uma nova situação. $^{18}$

O Direito pode ser entendido como atitude interpretativa, na medida em que corresponde a uma certa apariçăo do sentido ençuanto fruto da comunidade que realiza justiça. De fato, o juiz está vinculado não somente pelo caso. mas pelo conjunto de determinações que pressionam sua decisão para decidir abrigando argumentos de principio, mas não os de política.

Mas, o Direito não pode simplesmente ser visto como fruto da legalidade estrita, mas sim como instrumento que realiza valores e expectativas de justiça que lhe são anteriores. Mais que isto, é um récit que se pratica e se constrói fazendo com que algo se some à estrutura da concepção de justiça do ontem, para que se torne melhor. A noção de história demonstrada nesta leitura de Dworkin sobre o processo de construção da justiça é fundamentalmente cíclico-evolutiva, na medida em que o ontem é remanejado a cada case para ser tornado o "melhor possível" como objeto de uma demanda judicial. "Eu disse que nós temos por objetivo fazer do objeto da interpretação o melhor que ele puder ser" 190 ontem está sempre recebendo ajustes, adequações e acomodações para caber no hoje. Nesta perspectiva i que o Direito, enquanto conceito, será considerado fruto da concepção histórica de justiça de um conjunto de participantes (envolvidos em uma história, em uma mundividência, etc), e não poderá se descolar daquilo que são as próprias práticas sociais.

$\mathrm{Na}$ construção teórica dwrokiniana, duas regras presidem a idéia da interpretação: a primeira consiste à 'conveniência : esta é a fase do levantamento dos casos relativos à situação a ser decidida, bem como à empírica constatação dos argumentos cabiveis; a segunda corresponde ao 'valor': trata-se da escolha do valor de justiça que se resolve acolher para orientar o processo de seleção dos argumentos a serem acolhidus. de acordo com a 'moral política', ou seja, de acordo com a idéia de que a justiça não prescinde da igualdade para se realizar. Isto quer dizer que a posição teórica de Dworkin não se afasta completamente da idéia de que os direitos individuais devam ser

Casien; MARYIOLI, Aglaé. História da filosofia do direito. Tradução Mauricio de Andrade. São Paulo: Manole. 2005. p. 42I).

18 A respeito: "É certamente dai que résulta a definição do dircito como coerência narrativa, isto é, a retomada ininterrupta da história jurídica passada e sua reconstrução interpretativa que, nesse sentido. não trai nem o conteúdo dessa história, nem sua estrutura institucional" (BILLIER, Jean-Casien: MARYIOLI, Aglać. Ilistória da filosofia do direilo. Tradução Maurício de Andrade. São Paulu: Manole, 2005. p. 423).

19 DWORKIN, Ronald. Direito, filosofia e interpretação. Cadernos da escola do legislativo, Bclo Horizonte, $v$. 3. n. 5. p. 44-71, jan.'jun., 1997. p. 6?. 
protegidos. nem tampouco que a idéia de igualdade deva ser abolida da reflexão sobre o justo e o injusto.

Afinal, a pergunta aqui passa a ser: o que é a moral política? E esta pergunta é importante exatamente porque permite vislumbrar a posição teórica de Dworkin, como liberal. A pergunta sobre qual seja a moral política nos leva à idćia da solução correta para o caso controverso ou dificil (hard case): igual respeito e igual atenção. ${ }^{20}$ Esta fórmula registra um importante passo evolutivo dentro do pensamento de Dworkin, isto porque, em sua primeira fase, revela-se simplesmente como um liberal, que se dedica a enfatizar a importância do valor kantiano da autonomia individual. Nesta fase, desenvolve suas concepções na base da defesa do Estado liberal não-intervencionista, ou intervencionista na medida da necessidade de proteção das liberdades individuais. Nesta medida, o bem privado de cada um é simplesmente algo de interesse dos particulares, sendo a justiça uma tarefa alheia a isto, pois o murcado define o espaço da satisfação da noção de felicidade (escolha dos melhores bens para si) individual de cada um. Dworkin, em sua scgunda fase, passa a entender que a satisfação do bem particular de cada um (privado) não pode ser conquistada sem que alguns elementos de justiça (público) intervenham para o consentimento da realização deste bem particular. Ambos, bem público e bem particular, se misturam. porque se complementam. A justiça passa a ser entendida como condição de bem-estar para a realização dos indivíduos. Aqui, portanto, Dworkin revela-se nem um liberal, nem um comunitarista, mas um teórico da terceira via ou da conciliação. Nesta segunda fase, sem igual respeito e sem igual atenção, ${ }^{21}$ não há a possibilidade de bem privado e bem público se somarem. ${ }^{22}$

\section{Hermenêutica, razoabilidade e a coerência do Direito}

Suas reflexões são precisas no sentido de se inclinarem pulo viés da interpretação à discussão da própria noção de Direito; a questão da interpretação não é, de modo algum um. capítulo à latere da discussão de como o Direito se operacionaliza na prática, mas é de fato um aspecto crucial do desenvolvimento do próprio Direito, algo que

\footnotetext{
20 "Igual respeito e igual atenção, esta ė a norma fundamental da moral politica dworkiniana" (BILLIER. JeanCasien; MARYIOLl, Aglaé. Hisıória da filosofia do direito. Tradução Mauricio de Andrade. São Paulo: Manole, 2005. p. 426).

21 "A justiça, sem ser uma componente de nosso bem-estar. é contudo a condição de sua possibilidade" (BILLIER, Jean-Casien; MARYIOLl, Aglaé. História da filosofia do direito. Tradução Mauricio du Andrade. São Paulo: Manole. 2005. p. 426).

22 "Em outras palavras, o segundo Dworkin reconhece que a idéia do bem não é exclusivamente de ordem privada, mas também de ordem pública, aderindo assim às teses do filósofo canadense Will Kymlicka" (BILLIER, Jean-Casien; MARYIOLI, Aglaé. Hisı́ria da filosofia do direito. Tradução Mauricio de Andrade. São Paulo: Manole, 2005. p. 425),
} 
nos consente compreender sua idéia de que o Direito não se exaure em ser um conjunto de normas, pois pressupõe, de fato, além de regras, estas reconhecidas pelo positivismo como únicas formas de manifestação da juridicidade, também princípios, estes igualmente vinculantes da atividade judicial.

Normas e principios, portanto, compõem o sistema jurídico, na medida em que normas jurídicas válidas se aplicam, e normas jurídicas inválidas não se aplicam, enquanto que princípios sempre se aplicam, com maior ou menor intensidade aqui e ali, mas sempre serão considerados subsídios para que a interpretação de cada caso esteja escorada em valores morais de grande força e peso sócio-institucional. ${ }^{23}$

É certo, no entanto, que a invocabilidade de regras é mais usual que a de princípios; isto decorre não somente da própria consolidação de certas matérias em leis e praxes judiciais, por possuírem fácil acesso à argumentação dos pleiteantes, mas sobretudo porque a maior necessidade do uso de princípios se dá com o aumento da insegurança jurídica do terreno decisório no qual esteja o juiz pisando. A partir daí se pode perguntar: há norma para o caso concreto? (lacuna); havendo norma para o caso, ela é direta e objetivamente precisa para o caso? (ambigüidade); havendo norma para o caso, ela é a única a ser aplicada, e, em não sendo, com quais normas conflita e quais as opções para a decidibilidade? (antinomia). A partir destas indagações é que se percebe que o juiz estará agindo por princípios, sobretudo mas não exclusivamente -, quando se deparar com os chamados casos dificeis (hard cases), ${ }^{24}$ muito comuns em matéria de alta complexidade que chegam para exame das Cortes Superiores. Os hard cases são exatamente aqueles casos para os quais seja uma decisão política, seja uma decisão jurídica parecem ser invocadas como mecanismo de solução da controvérsia. Daí a idéia de que as funções legislativa e judicial, nestas hipóteses, se aproximam. ${ }^{25}$

Os principios (isonomia processual das partes, amplo contraditório como garantia legal, pactos devem ser observados...) funcionam, para o juiz, como instrumentos de auxílio à decisão judicial, e, para o Direito, como dados fundamentais para a

23 Cf. SALDAÑA. Javier. Derechos morales o derechos naturales. Boletin Mexicano de Derecho Comparado, Universidad Autónoma de México, México, n. 90. p. 1.216, sept.-nov., 1997.

24 "In caso es dificil si existe incerteza, sea porque existen varias normas aplicables que determinan sentencias distintas - porque las normas son contradictorias - sea porque no existe norma exatamente aplicable" (RUMERO. Marcelo Troncoso. Ronald Dworkin: sobre la teoría de la función judicial. Revista de Derecho, Universidad de Concepción, n. 193, p. 101-105, enero-junio, 1993. p. 104). Também: "Em seu aspecto descritivo, a teses dos direitos sustenta que, nos casos dificeis, as decisões judiciais são caracteristicamente geradas por principios, não por politicas" (DWORKIN. Ronald. Levando os direitos a sério. São Paulo: Martins Fontes, 2002. p. 151).

25 "Contudo, se o caso em questão for um caso dificil, em que nenhuma regra estabelecida dita uma decisão em qualquer direção, pode pareccr que uma decisão apropriada possa ser gerada scja por princípios, seja por politicos" (DWORKIN, Ronald. Levando os direitos a sério. São Paulo: Martins Fontes. 2002. p. 131). 
construção da validade do sistıma, dado este que leva Dworkin a racionar pensando na coerência de todo do Direito, incluindo os princípios, e não-somente na coerência das regras entre si. ${ }^{26}$

Quando se passa a pensar a coerência do Direito como uma grande mecânica que reúne regras e princípios, a razoabilidade (fairnes) do Direito deixa de depender simplesmente da lógica intra-sistêmica das regras entre si (o que foi decretado pelo legislador) e passa a depender da lógica inter-sistèmica (o que as instituições reconhecem como práticas legitimas socialmente), em face da recorribilidade à história e à práxis em torno da justiça. Se a aplicação do Direito sempre depende de uma releitura do passado, de forma a retornar bem melhor... história e interpretação andam juntas na definição e circunscrição do que suja a idéia de 'coerência' do Direito. Fm sua reflıxão, está ausentc a preocupação com a verdade, enquanto correspondência (adequatio mens ad rerum), na medida em que caminha no sentido da afirmação da idéia de uma outra forma de verdade, enquanto coerência. ${ }^{27}$

Os princípios são, portanto, vinculativos para a atividade do juiz, além de se considerar que se constróem no embate histórico dos valores morais. Some-se a estes dois fatores a idéia de que são, por essência, abertos e vagos pela indefinição de seus conteúdos semânticos, porosos para experiências em constante processo de construção. Dworkin, portanto, não somente reconhece a vagueza da linguagem como, também, reconhece a subjutividade da interpretação, incluindo-as na lógica do processo decisório e na avaliação do funcionamento da idéia de Direito. O problema da vagueza ${ }^{28}$ pode ser superado pela adoção de princípios como escoras da decisão, e o problema da subjetividade pelo compartilhamento de valores contidos nos princípios. já que estes são gestados ao longo da tradição social e jurídica. Assim, o juiz "na sua interpretação, é acompanhado por uma teoria política de fundamento histórico, baseada em estruturas. práticas, consensos" 29

Não se trata de pensar como o positivismo, ou tudo (ordenamento normativo completo) ou nada (discricionariedade absoluta do juiz), mas sim de um modo

26 Cf. SILVA FIL.HO. José Carlos Moreira da. Dworkin e os principios: os avanços da hermenéutica critica do direito. Estudos juridicos, v. 31, n. 81.p. 73-94, jan./abr. 1998.

27 "A teoria da verdade-correspondencia dos fatos com o real é assim substituída por ayuela da verdadecoerència" (BILLIER, Jean-Casien; MARYIOLI, Aglaé. Hisıória da filosofia do direito. Traduçào Maurício de Andrade. São Paulo: Manole, 2005. p. 42I).

28 Este problema da vagueza está não somente nos principios, mas sobretudo na linguagem do próprio Direito. especialmente que se está diante do sistema de common law: "As leis e as regras do direito costumeiro (common law) são quase sempre vagas e devem sur interpretadas antes de se poder aplicá-las aos novos casos" (DWORKIN, Ronald. Levando os direitos a sério. São Paulo: Martins Fontes. 2002. p. 128).

29 SILVA FILHO, José Carlos Moreira da. Dworkin e os princípios: os avanços da hermenèutica critica do direito. Estudos juridicos. v. 31, n. 81, p. 73-94, jan./ abr. 1998. p. 91. 
em que se pode vincular o juiz a dados constantes do sistema juridico, mas não contidos em regras específicas (ou explícitas) para o caso concreto: os princípios. Não que estes ofereçam pura segurança ao juiz no momento da decisão, pois princípios poden ser lidos por vieses diferentes por dois juízes diferentes. Por exemplo, como afirma Dworkin, diante de uma mesma querela, um juiz de vanguarda e um juiz simpatizante do positivismo, podem decidir de modos dispares; o juiz de índole positivista. vinculado à idéia de previsibilidade, pensaria que, se a lei concede tal possibilidade, o próprio assassino herde na sucessão os bens daquele que matou (!), apesar de entender que o legislador deveria mudar a legislação no futuro. ${ }^{30} \mathrm{O}$ outro juiz poderia pensar que existem principios (ainda que a lei diga o contrário) no ordenamento contrários ao favorecimento do praticante de um assassinato, especialmente se se trata de receber a herança da vítima do ato criminoso.

A subjetividade, portanto, não está eliminada do processo hermenêutico, pelo contrário. A interpretação sempre será algo de natureza subjetiva, afirma Dworkin. "Para cada pessoa, há uma interpretação diferente" "Este pensamento é extremamente democrático, porque abre exatamente a vivência do Direito à vivência da diferença e da complexidade, fugindo portanto à base de inspiração do raciocínio de toda a fundamentação fillosófica da modernidade positivista: a busca pela homogeneidade. Mais que isto, a concepção hermenêutica de Dworkin permite que o juiz se libere através de suas decisões suas convicções, suas idéias pessoais, e as miscigene ao conjunto dos valores institucionais aplicáveis. ${ }^{32}$ Isto não quer dizer que o juiz simplesmente poderá tomar decisões arbitrárias, ou simplesmente pensará conforme suas inclinações puramente pessoais, mas sim que estes argumentos deverão se mesclar. como efetivamente se mesclam, a valores institucionalizados e consagrados na prática jurídica. Aliás, na prática: "Um juiz, porém. só muito raramente irá mostrar este tipo de independência. Tentará. sempre, associar a justificação que ele fornece para uma decisão original às decisões que outros juízes ou funcionários tomaram no passado" 33

Sendo a interpretação a espinha dorsal da atividade juridica, é de se concluir que o próprio Direito não poderá se pleitcar jamais uma condição puramente objetiva, mas

${ }^{30} \mathrm{Cr}$. DWORKIN. Ronald. Direito, filosofia e interpretaçào. Cadernos da escola do legislativo. Belo Horizonte, v. 3, n. 5, p. 44-71, jan./jun., 1997. p. 60-61.

31 DWORKIN, Ronald. Direito. filosofia e interpretação. Cadernos da c'scola do legislativo. Belo Horizonte, v. 3, n. 5, p. 44-71, jan./jun., 1997, p. 54.

32 "O conceito de direito, afirmará Dworkin, nunca é independente de uma concepção do direito e da justiça" (BILlLIER, Jean-Casien; MARYIOLI, Aglaè. História da filosofia do direiro. Traduçào Mauricio de Andrade. São Paulo: Manolc. 2005. p. 422).

33 DWORKIN. Ronald. I.evando os direitos a sério. São Paulo: Martins Fontes. 2002. p. 175. 
sim uma condição mais subjetiva. ${ }^{34} \dot{E}$ isto que alimenta o turbilhão de visões e aplicações do Direito, é isto que aquece a fornalha das discussões judiciais, é isto que caracteriza o processo de dialética construção social da justiça, o que faz com que as incertezas jurídicas sejam simplesmente "derivação da incerteza moral ou política" 35 Ao contrário de afastar a idéia do bem do Direito, ou mesmo de afastar a compaixão e outros sentimentos da esfera da prática da justiça, Dworkin acentua a presença destas no seio da atividade construtora de valores práticos afirmadores da justiça, como se vê neste trecho da transcrição de uma de suas conferência (Atenas, 1994): "Então. haveremos de conduzir a justiça dentro da bondade, não apenas racionalmente, mas emocionalmente; e, assim. haveremos de conduzir melhor, com mais dignidade e com menos incoerência a responsabilidade pessoal de nossas vidas" 36

4. Argumentos de principio e argumentos de política: hard cises e o desafio à aplicação do direito

A aplicação de um princípio a um caso concreto, especialmente em hard cases, demanda do julgador o uso não de critérios fixos (estes que são inexistentes), mas um balanceamento, em que se ressalta a idéia de 'peso' de um princípio. Não-somente inexistem estes critérios fixos que consintam a formulação de uma racionalidade abstrata sobre os princípios, como também não há nada no pensamento de Dworkin que autorize a identificar qualquer tipo de hierarquia entre os próprios princípios; ${ }^{3 i}$ então, in abstructo, nenhum princípio vale mais ou menos que outro, a não ser diante de uma situação em que se evidencie que seu uso concreto deva ser preponderante com relação ao de um outro princípio. Um princípio (igualdade) poderá pesar mais num caso do que noutro, ou pesar mais do que um outro princípio (liberdade de mercado). ${ }^{38}$

Mas, os princípios não querem dizer livre opção de julgar pelo juiz, o que faria de cada sentenciador, nos casos concretos, alguém livre para iniciar uma nova

34 CE. DWORKIN. Ronald. Direito, lilosofia e interpretação. Cadernos da escola do legislarivo. Belo Horizonte, v. 3, n. 5, p. 44-7I. jan./jun., 1997. p. 54.

35 DWORKIN, Ronald. Le'vando os direitos a sério. São Paulo: Martins Fontes, 2002. p. 128).

35 SILVA FILHO. José Carlos Moreira da. Dworkin e os principios: os avanços da hermenèutica critica do direito. Fstudos juridicos, v. 31, n. 81. p. 73-94, jan./ abr. 1998. p. 69.

36 DWORKIN, Ronald. A bondade da justiça. Justiça do direilo. Passo Fundo, v. 13, n. 13. p. 125-134. 1999. p. 134.

37 Assiste razào a Romero, quando interpreta o pensamento de Dworkin para alïmar que nãu pode haver hierarquia pré-definida entre os principios. A esle respeito, vide ROMERO. Marcelo Troncoso. Ronald Dworkin: sobre la tcoria de la función judicial. Revista de Derecho. Universidad de Concepción, n. 193. p. 101-105, enero-junio, 1993.

38 Cf. SILVA FILHO. José Carlos Moreira da. Dwurkin e os principios: os avanços da hermenèutica crítica do dircito. Estudos juridicos, v. 31, n. 81, p. 73-94, jan. abr. 1998. p. 86. 
proposta normativa, cm atitude semelhante à liburdade criadora do legislador. "O juiz continua tendo o dever, mesmo nos casos difíceis, de descobrir quais são os direitos das partes. e não de inventar novos direitos retroativamente" ${ }^{39}$ Ora, em Dworkin isto é claro: a eqüidade do juiz nada tem a ver com a auctoritas do legislador, pois a atividade do juiz. se assemelha à atividade do legislador. Este age por políticas, ou segue diretrizes, que são decisões fundamentais atinentes a demandas da coletividade. seguindo imperativos sociais, econômicos e políticos cie decisão e escolha. A distinção não pode ser mais clara, quando Dworkin afirma: "Os argumentos de princípio são argumentos destinados a estabelecer um direito individua; os argumentos de política são argumentos destinados a estabelecer um objetivo coletivo. Os principios são proposições que descrevem direitos; as políticas são proposições que descrevem objetivos" ${ }^{40} \mathrm{O}$ juiz, por sua vez, age (e deve agir), não por escolhas políticas (ou por preferências político-pessoais), e sim de acordo com princípios, ou scja, "imperativos de justiça ou eqüidade" 41 que possuem valor por si só determinados.

Dworkin. a partir de uma analogia com a idéia de escritura de um romance compartilhada entre vários autores ("Gostaria agora de comparar o desenvolvimento do Direito à elaboração desse, digamos, romance em cadeia"), ${ }^{22}$ não acredita que os juízes, mesmo em caso difíceis (hard cases), estejam autorizados a criar, e simplesmente criar, direito novo, na medida em que ao agirem, o fazem de acordo com uma tradição, pois tomam o romance já pré-escrito, em parte, com a tarefa de dar-lhe continuidade ou dar acabamento definitivo. Isto significa que o juiz não está a autorizado a criar uma estória desvinculada de sua escrita anterior, muito menos que o juiz possa se desvencilhar do dever de considerar a coerência narrativa da ordem discursiva com a qual processa a estória ou the põe um término. ${ }^{43}$ Desta forma, não há somente a imposição dos valores subjetivos do juiz ao caso concreto. mas uma atividade que leva em consideração o resto da estória escrita pelos demais atores sociais (agentes econômicos, morais, religiosos...) e jurídicos (legisladores, politicos, juízes, advogados...).

O papel da sua teoria dos princípios, portanto, é não-somente fundamıntal para discutir coerência c narratividade, na construção da razoabilidade (fairnes) da justiça

39 DWORKIN. Ronald. Leviundo os dirciros a sério. São Paulo: Manins Fontes, 2002. p. 128. p. 127.

to DWORKIN, Ronald. Levando os direitos a sério. São Paulo: Martins Fontes, 2002. p. I4I.

41 Silva Filho, José Carlos Moreira da. Dworkin e os princípios: os avanços da hermenêutica crítica do direito. Estudos juridicos, v. 31. n. 81, p. 73-94, jan./abr. 1998. p. 87.

42 DWORKIN. Ronald. Direito, filosofia e interpretação. Cadernos da escola do legislativo, Belo Horizonte, $v$. 3, n. 5. p. 44-71, jan./jun.. 1997. p. 51.

43 Há um apelo forte à idéia de coerência na obra de Dworkin. A este respcito, consulte-se CHUEIRI, Vera Karam. Considerações em torno da ieoria da cocrência narrativa de Ronald Dworkin. Seqüéncia, Florianópolis, n. 23, p. 73-77, dez. 1991. p. 74. 
(justice) como, também, determinante para circunscrever os limites entre a esfera da política e a esfera da juridicidade. ${ }^{44}$ De fato, quando Dworkin prefere optar pela discussão que predispõe o juiz a levar a sério os direitos, nem denegando-os às partes, por se deparar com um caso difícil, nem agindo como político, mas sim criando decisão razoável, pelo balanço entre princípios com pesos relativos às situações, conferindo-se à prática jurídica uma espécie de ajuste de razoabilidade conforme a necessidade de eqüidade demandada pelas exigências casuísticas. É neste sentido que se expressa. dizendo: "Não-obstante. defendo a tese de que as decisões judiciais nos casos civis, mesmo em casos dificeis como o da Spartan Steel, são e devem ser, de maneira característica, gerados por princípios, e não por políticas" 45

A distinção, portanto, entre argumentos de princípios e argumentos de política (policy), é fundamental. Os segundos justificam uma decisão política. conferindo algum toque de racionalidade à decisão acerca de algum objetivo coletivo da comunidade, considerada em sua totalidade. Os primeiros também podem ser ditos argumentos que justificam uma decisão política, mas agora mostrando que a decisão (política) está respeitando e garantindo um direito específico, pertinente a um ou a vários membros do corpo social. ${ }^{46}$ Portanto, não é tarefa do julgador agir como alguém que simplesmente cria ex nihilo direito, na medida em que nem recebeu mandato social para isto, e muito menos pode surpreender as partes em meio ao processo com direitos novos, ao que correspondem deveres (post factum) da parte perdedora, antes por elas desconhecidos. ${ }^{47}$

O Direito não se confundirá, nesta medida, com uma ação de poder (imposição de escolha fundada na força e baseada na idéia de uma política a atender metas sociais), mas, de fato, exercerá uma atividade censória do poder, na medida em que o uso da força acaba por ganhar guarida somente quando e onde a força for justificável pela imperatividade de princípios sociais e pela vinculatividade de valores morais fundantes do

44 De fato: "As decisões jurisdicionais nos casos dificeis não devem se basear em argumentos de política (politics) que surgem de uma problemática de objetivos a realizar em uma comunidade - o crescimento econômico, por exemplo . mas em argumentos de princípio pelos quais as autoridades de aplicação do direito fixam os direitos subjetivos das partes no momento dos fatos" (BILLIER, Jean-Casien; MARYIULI. Aglaé. Hisı́ria da filosofia do direilo. Tradução Maurício de Andrade. São Paulo: Manole, 2005. p. 426).

4 DWORKIN. Ronald. Levando os direiros a sério. São Paulo: Martins Fontes, 2002. p. 132.

$\$ 6$ CF. DWORKIN, Ronald. Levando os direitos a sério. São Paulo: Martins Fontes, 2002. p. 129.

47 "A conhecida história de que a decisão judicial deve ser subordinada à legislação é sustentada por duas objeçōes à originalidade judicial. De acordu com a primeira. uma comunidade deve ser governada por homens e mulheres eleitos pela maioria c responsáveis perante ela. Tendo em vista que. em sua maior parte, os juizes não são eleitos, e como na prática eles não são responsáveis perante o eleitorado, como ocorre com os legisladores, o pressuposto acima parece comprometer essa proposição quando os juizes criam leis. A segunda objeção argumenta que, se um juiz criar uma nova lei e aplicá-la retroativamente ao caso qui tem diantc de si, a parte perdedora será punida, não por ter violado algum dever que tivesse, mas sim por ter violado um novo dever, criado pelo juiz após o fato" (DWORKIN, Ronald. Levando os direitos a sério. São Paulo: Martins Fontes, 2002. p. 1.32). 
pensamentu jurídico predominante. Mas, isto não-autoriza a dizer que direito nada tem a ver com política, ou como moral, ${ }^{48}$ como queriam us positivistas, na medida em que os argumentos utilizados pelos juristas não se encontram alheios aos processos históricos de construção dos valores. Com Habermas: "O direito situa-se entre a política e a mural: Dworkin dumonstra que o discurso juridico trabalha, não somente com argumentos políticos que visam ao estabelecimento de objelivos, mas também com argumentos de fundamentação moral" 49

\section{A crítica ao juiz-Hércules: a polêmica com o modelo de Habermas}

Em certo momento de suas investigações, Dworkin cria a idéia de um juiz.modelo. um juiz-filósofo, a que apelida de Hércules, a quem atribui potenciais extraordinários para construir sua discussão sobre a força imperativa de sua atividade aplicativa. Trata-se de uma criação importante, assim como o rei-filósofo o é na teoria politica platônica, ou como a posição original o é na teoria de John Ralws, como referencial metafórico do discurso, para plasmar a prática judicial onde predomina a prudência (phrónesis, para os gregos) no momento da decisão, na medida em que este juiz Hércules é incorruptivel, na medida em que não se curva a argumentos políticos, na medida em que age com correção na avaliação dos princípios a serem aplicados aos casos concretos. Mais que isto, Hércules é aquele herói que consagra toda a força da própria reflexão sobre a eqüidade levada adiante por Dworkin ("Hércules concluirá que sua doutrina da eqüidade oferece a única explicação adequada da prática do precedente em sua totalidade"), ${ }^{50} \mathrm{e}$, exatamente por isso, não segue teorias clássicas da decisão judicial. mas sim a idéia de que, ao aplicar o direito, age como a lei ou precedente exigem, embora tomando suas decisões com convicção pessoal, sem que estas tenham força independente dos argumentos racionais utilizados para justificar o raciocinio judicial utilizado em cada caso concreto. ${ }^{51}$ Hércules é o simbolo da união entre teoria e prática jurídicas. ${ }^{52}$

Por isso a criação da figura que ocupa um locus explicativo em sua teoria, ainda que scja acusada de provocar um apelo a ideal inocente de racionalidade

48 Cf. BURTON, Steven J. Ronald Dworkin and legal positivism. Iowa Law Review. University lowa, v. 73, n. 01. p. 109-129, oct. 1987.

49 HABERMAS. Jürgen. Direito e democracia: entre facticidade e validade. Tradução de Flávio Beno Siebeneichler. 3. ed. Rio de Janeiro: Tempo Brasileiro, 2003. v. II, p. 218.

so DWORKIN, Ronald. Levando os direitos a sério. São Paulo: Martins Fontes, 2002. p. 177.

51 DWORKIN, Ronald. Levando os direitos a sério. São Paulo: Martins Fontes, 2002. p. 184.

52 Cf. LENOBLE, Jacques. La théorie de la cohérence narrative en droit: le débal Dworkin-Mcl ormick. irchives de Philosophie du Droit. Paris. n. 33. p. 121-139, 1988, p. 129. 
perfectibilizável. ${ }^{53}$ Com Dworkin: "Podemos, portanto, examinar de que modo um juiz filósofo poderia desenvolver, nos casos apropriados, teorias sobre aquilo que a intenção legislativa e os princípios jurídicos requerem. Descobriremos que ele formula cssas teorias da mesma maneira que um árbitro filosófico construiria as características de um jogo. Para esse fim, eu inventei um jurista de capacidade, sabedoria, paciência e sagacidade sobrehumanas, a quem chamarei de Hércules" ${ }^{54}$ Hércules serve também como uma espécie de guardião-observador da coerência de todo do sistema, exatamente por postar-se com um olhar totalizante do sistema na condição de quem o avalia em sua inteireza. Fle é assim chamado, porque deve construir um esquema de princípios abstratos e concretos para a justificação dos precedentes do direito costumeiro, a partir de princípios, e para a justificação das regras de direito constitucionais e direito positivo em geral. ${ }^{55}$

Este juiz-ideal plasma todas as características necessárias para Dworkin argumentar com liberdade como seria se..., facultando a que a hipótese de trabalho esteja recoberta por uma práxis inventiva e coerente, por isso isenta dos aspectos mais comezinhos da atividade judicial real e corriqueira dos tribunais. A crítica, neste momento levanta um problema de profundidade. na avaliação da reflexão de Dworkin, apontando que sua teoria tem por exigência a necessidade de sempre contar com a moralidade do juiz, ou do super-juiz, para reforçar sua própria tese. ${ }^{56}$ Então, assim distorcida por este fator, torna-se irreal e não-praticável.

É um pouco esta a crítica de Jürgen Habermas. que aponta a incoerência da concepção de Dworkin quando apela para a idéia de um jui૮ com acesso privilegiado à justiça, na medida em que quer considerar atores reais em processo dialógico, construindo por fatores do próprio diálogo, a justiça. ${ }^{57} \mathrm{O}$ entendimento mútuo entre indivíduos em sociedade surgirá quando, e somente quando, os sujeitos falantes se prostrarem diante do discurso, mediante atitude consensual, e jamais imposta ou manipulada pela outra parte falante, por práticas comuns, com pretensões de aceitarem condições comuns, que induzam a formação de um espaço de convívio entre o ego e o alter, ou seja, quando se trata de uma ação recíproca e mútua, onde ambos os atores harmonizam seus planos de

53 HABA, Henrique P. Rehabilitación Del no-saber em la actual teoria Del derecho: el bluff Dworkin. Doxa: Cuadernos de Filosofia del Derecho, n. 24, p. 165-200, 2001. p. 174.

s4 DWORKIN, Ronald. Levando os direitos a sério. São Paulo: Martins Fontes, 2002. p. 165.

s5 DWORKIN, Ronald. Levando os direttos a sério. São Paulo: Martins Fontes, 2002. p. 182.

56 Destaque-se a crítica de SILVA FIL HO, José Carlos Moreira da. Dworkin e os principios: os avanços da hermenèutica critica do direito. Estudes juridicos, v. 31, n. 81, p. 73-94, jan. abr. 1998. p. 92.

57 "A teoria da justiça do filósofo americano, todavia, não escapa à crítica da J. Habermas quanto ao lugar que ocupa seu juiz ideal (Hércules), que dispõe de um acesso privilegiado à Verdade. No lugar dessa concepção deontologica (embora, paradoxalmente, substancial) e monológica da justiça, o filósofo alemão vai tentar instituir uma concepção processual e dialógica" (BILIItIR, Jean-Casien; MARYIOLI. Aglaé. História da filosofia do dircito. 'Tradução Mauricio de Andrade. São Paulo: Manole, 2005. p. 429). 
ação, conferindo a eles um certo sentido comum comunicativo. ${ }^{58}$ Em Dworkin, a figura do juiz-Hércules acaba tornando opaca sua concepção, também acertada, de que as instituições, os costumes e as práticas sociais já estão imbutidas na leitura do récit anteriormente escrito pelos outros autores do romance de múltipla autoria, o que desautorizaria, com toda propriedade a critica que se lhe dirigem. De qualquer forma, o modelo de Habermas ressalta, à evidência, que não há individuos com acesso privilegiado à verdade, à razão, à prudência, mas o que deve haver é sim uma comunidade consciente da importância da linguagem como fator de determinação dos sentidos da justiça, por isso o apelo a uma racionalidade compartilhada, e não individual: "Ao contrário, falo em agir comunicativo quando os atores tratam de harmonizar internamente seus planos de ação e de só perseguir suas respectivas metas sob a condição de um acordo existente ou a se negociar sobre a situação e as conseqüîncias esperadas. Em ambos os casos, a estrutura telcológica da ação é pressuposta na medida em que se atribui aos atores a capacidade de agir em vista de um objetivo c o interesse em executar seus planos de ação" 59

\section{Conclusões}

A reflexão de Dworkin, centrada na idéia de que o Direitu nunca se pode alhear aos processos de linguagem e que, portanto, é produto do processo hermenêutico, não desconsidera e nem menospruza a importância do conscrvantismo de valores que medra no processo de aplicação de um sistema de regras em um conjunto de casos concretos (hard or easy cases). Mas, casos dificeis (hard cases) se definem muito mais problemáticos, porque tornam necessário ao juiz proceder a uma escolha, que recorre a critérios de justiça (justice) externos à ordem jurídica concreta, abrindo caminho para decisões polêmicas que parecem convidar o jurista a pensar os limites entre Direito e Política.

A resposta de Dworkin a esta perplexidade não reafirma as teses positivistas. e muito menos abre campo para um autorizativo indeterminado para que o juiz proceda simplesmente conformc seu arbitrio. Sua reflexão aposta na idéia de que um sistema somente pode ser considerado coerente e completo se avaliados os princípios que a ele pertencem, estes qui às vezes estão consagrados em regras, mas quc, em sendo coisas separadas delas, continuam c possuir a mesma capacidade de vinculação da decisão que as próprias regras. Nesta medida é que, no esforço de comprecnder a dinâmica dos

58 Cf. HABBERAS, Jürgùn. Consciência Moral e Agir Comunicativo. Traduçào de Guido A. de Almeida. Rio de Janeiro: Tempo Brasileiro, 1989. p. 164 e 165.

59 HABERMAS, Jürgen. Consciência Moral e Agir Comunicutivo. Tradução de Guido A. de Almeida. Rio de Janeiro: Tempn Brasileiro. 1989. p. 164 e 165. 
precedentes é que Dworkin chega à idéia de que o sistema somente funciona porque princípios informam a completude do sistema, o que por si só é argumento bastante para informar ao juiz que o seu papel crítico não está em reproduzir regras do ordenamento, repetir a lógica dos julgados anteriores, nem mesmo criar como se fosse legislador, mas sim ponderar o peso dos valores que estão em debate, especialmente diante de situaçõeslimite, ou de hard cases. Aí está não-só a chave para a compreensão do papel do juizHércules em seu pensamento, mas sobretudo a chave para a compreensão da idéia de que o raciocinio que legitima a lógica jurídica não é de pura racionalidade apodítica, mas sim de uma espécie de ação mental que pratica permanente e inexaurivelmente a busca do razoável.

São Paulo, dezembro de 2005.

Referências

BILLIER, Jean-Cassien; MARYIOLI, Aglaé. História da filosofia do direito. Tradução Maurício de Andrade. São Paulo: Manole, 2005.

BIT TAR, l:duardo C. B. Linguagem jurídica. 2.ed. São Paulo: Saraiva, 2003.

BLENO, Roberto. Dos critérios de justiça em Dworkin e Rawls. Revista de Direito Constitucional e Internacional, Instituto Brasileiro e Direito Constitucional, São Paulo, Revista dos Tribunais, p. 171-182, jul.-set., 2002.

BURTON, Steven J. Ronald Dworkin and legal positivism. lowa Law Review, University of lowa, v. 73, n. 01, p. 109-129, oct. 1987.

(HUEIRI, Vera Karam. Considerações em torno da teoria da coerência narrativa de Ronald Dworkin. Seqüencia, Florianópolis, Universidade Federal de Santa Catarina, n. 23, p. 73-77, dez., 1991.

DWORKIN, Ronald. Direito, filosofia e interpretação. Cadernos da escola do legislativo, Belo Horizonte, v. 3, n. 5. p. 44-71, jan./jun., 1997.

DWORKIN. Ronald. Levando o direito a sério. Tradução. São Paulo: Martins Fontes. 2002.

DWORKIN, Ronald. A bondade da justiça. Justiça do Direito, Passo Fundo, I'niversidade de Passo Fundo, Faculdade de Direito. E.DIUPF, v. 13, n. 13, p. 125-134, 1999.

DWORKIN. Ronald. What is equality? The place of liberty. Lowa Law Review, University of lowa, v. 73. n. 01. p. 01-55. oct. 1987. 
FERRAZ JUNIOR, Tércio Sampaio. Introdução ao estudo do direito. 3. ed. São Paulo: Atlas, 2001.

HABA, Enrique P. Rehabilitación del no-saber en la actual teoria del derecho: el bluff Dworkin. Doxa, Cuadernos de Filusofía del Derecho, n. 24, p. 165-200. 2001.

HABERMAS, Jürgen. Consciência moral e ugir comunicativo. Tradução de Guido A. de Almeida. Rio de Janeiro: Tempo Brasileiro, 1989.

HABERMAS, Jürgen. Direito e democracia: cntre facticidade e validade. Tradução de Flávio Beno Siebeneichler. 3. ed. Rio de Janeiro: Tempo Brasileiro, 2003.

HART, H. L. A. O conceitu de direito. Tradução de A. Ribeiro Mendes. Lisboa: Fundação Calouste Gulbenkian, 1986.

KELSEN, Hans. O problema da justiça. Tradução de João Baptista Machado. 3. ed. São Paulo: Martins Fontes, 1998.

KELSEN, Hans. Teoriu pura do direito. Tradução de João Baptista Machado. 4. ed. Coimbra: Armênio Amado Lditor, 1976.

LENOBLE, Jacques. La théorie de la cohérence narrative en droit: le débat Dworkin-McCormick. Archives de Philosophie du Droit, Paris, Sirey, n. 33, p. 121-139, 1988.

MURICY, Marilia. Racionalidade do direito, justiça e interpretação. In: BOUCAULT, Carlos E. de Abreu; RODRIGUFZ, José Rodrigo. (Orgs.). Hermenêutica Plural. São Paulo: Martins Fontes, 2002.

PASTORE, Baldassare. Coerenza e integrità nella tcoria Del ragionamento giuridico di Ronald Dworkin. Rivista di Diritto Civile, Padova, Casa Editrice Dott. Antonio Milani, ano XXXVIII, n. 4, luglio-agosto. 1992.

PILUN. Almir José; DLTRA, Delamar José Volpato. Filosofia juridica contemporânea, justiça e dignidade do ser humano: John Rawls c Ronald Dworkin. In: WOLKMER, Antonio Carlos. (Org.) Fundamentos do humanismo juridico no Ocidente. São Paulo/ Florianópolis: Manole : Fundação Boitcux, p. 181-213.

ROMERO, Marcelo Troncoso. Ronald Dworkin: sobre la teoría de la función judicial. Revista de Derecho, Universidad de Concepción, Chile, n. 193, p. I01-105, encro-junio, 1993.

SALDAÑA, Javier. Derechos Morales o derechos naturales. Boletin Mexicano di Derecho Comparado, liniversidad Autónoma de México, México, n. 90, sept.-nov.. 1997.

SILVA FILHO, José Carlos Moreira da. Dworkin ¿ os princípios: os avanços da hermunciutica critica do direito. Estudos juridicos, v. 31. n. 81, p. 73-94 jan./abr. 1998. 